\section{Twenty-four-hour intraocular pressure and ocular perfusion pressure characteristics in newly diagnosed patients with normal tension glaucoma}

L Quaranta', A Katsanos², I Riva', A Dastiridou, F Oddone ${ }^{4}$, G Roberti ${ }^{4}$ and AGP Konstas ${ }^{5}$

\begin{abstract}
Purpose To determine the mean 24-h intraocular pressure (IOP) and mean ocular perfusion pressure (MOPP) characteristics of newly diagnosed, previously untreated, Caucasian, normal tension glaucoma (NTG) patients and to identify relationships between these features and visual field (VF) loss at diagnosis.
\end{abstract}

Methods Consecutive newly diagnosed NTG patients underwent 24-h habitual IOP and blood pressure (BP) monitoring. Parameters from pooled measurements obtained in the sitting (0800-2200 hours) and supine (1200-0600 hours) positions were compared and associations were sought with VF mean deviation (MD) and pattern standard deviation (PSD).

Results Sixty-two Caucasian NTG patients (24 men and 38 women) successfully completed circadian IOP and BP monitoring. In habitual position, 8 subjects (12.9\%) exhibited a diurnal acrophase, 42 subjects $(67.7 \%)$ demonstrated a nocturnal acrophase, one subject $(1.6 \%)$ showed a flat rhythm and 11 patients $(\mathbf{1 7 . 7} \%)$ revealed a biphasic/ polyphasic rhythm. Nighttime MOPP values (supine position) were significantly greater than diurnal values (sitting position); $(P<0.001)$. No association could be demonstrated between glaucomatous damage, as indicated by VF parameters, and either mean habitual 24 -h IOP $(P=0.20$ and $P=0.12$ for MD and PSD, respectively), or habitual 24-h MOPP $(P=0.96$ and 0.29 , for MD and PSD, respectively).

Conclusions In this cohort of Caucasian NTG patients, most patients exhibited a nocturnal IOP acrophase when evaluated in a habitual position. No association was found between 24-h IOP or MOPP and VF damage. Eye (2016) 30, 1481-1489; doi:10.1038/eye.2016.168; published online 29 July 2016

\section{Introduction}

Glaucoma comprises a multifactorial disease characterized by loss of retinal ganglion cells that leads to a distinctive optic neuropathy and associated visual field (VF) loss. ${ }^{1}$ The precise pathogenesis of open-angle glaucoma remains to be elucidated, but elevated intraocular pressure (IOP) is considered the principal risk factor for the development and progression of glaucomatous neuropathy. ${ }^{1}$ Currently, meaningful lowering of IOP is the only available therapeutic strategy in glaucoma. ${ }^{1,2}$ Importantly, recent evidence suggests that 24-h IOP characteristics may have an important role in the long-term prognosis of glaucoma. ${ }^{3-6}$

With the advent of large, well designed, population-based epidemiological studies it became apparent that a significant proportion of open-angle glaucoma cases presents with glaucomatous neuropathy and an IOP within the so called normal range $(21 \mathrm{mmHg}$ or less, ie, below the statistical upper limit of normal range). ${ }^{7,8}$ Most, but not all, clinicians consider normal tension glaucoma (NTG) a distinct clinical entity. ${ }^{9,10}$ It has been demonstrated that NTG patients are characterized by a pattern of VF damage closer to the fixation as compared with high-pressure glaucoma and that, within a NTG population, patients with IOP at, or below $15 \mathrm{mmHg}$ exhibit a significant higher risk for retinal nerve fibre layer defects closer to fixation. ${ }^{9,10}$
${ }^{1}$ Department of Medical and Surgical Specialties, Radiological Sciences and Public Health, University of Brescia, Brescia, Italy

${ }^{2}$ Ophthalmology Department, University of loannina, Ioannina, Greece

${ }^{3}$ Moorfields Eye Hospital, London, UK

${ }^{4}$ IRCCS Fondazione G.B. Bietti, Rome, Italy

${ }^{5}$ Glaucoma Unit, 1st University Department of Ophthalmology, AHEPA Hospital, Thessaloniki, Greece

Correspondence: L Quaranta, USVD 'Centro per lo Studio del Glaucoma', Piazzale Spedali, Civili 1, 25123 Brescia, Italy Tel: +390303995847; Fax: +39030396622. E-mail: luciano.quaranta@ unibs.it

Received: 22 February 2016 Accepted in revised form: 23 June 2016 Published online: 29 July 2016 
It is well documented that a proportion of treated openangle glaucoma patients continue to deteriorate despite a statistically significant and clinically meaningful IOP reduction. ${ }^{7,11}$ It may be that in these cases other pressureindependent factors are contributory. Several clinical trials have demonstrated the role of vascular factors as part of the multifaceted pathogenesis of open-angle glaucoma. ${ }^{12-14}$ A parameter that has been strongly associated with glaucoma prevalence and progression is ocular perfusion pressure (OPP).${ }^{15-22}$ More specifically, evidence has highlighted the role of reduced OPP in the incidence, ${ }^{16}$ prevalence, ${ }^{17-22}$ and progression of glaucomatous neuropathy ${ }^{15}$ in several ethnic groups. Particularly in NTG, increased OPP fluctuation has been linked to the severity of disease at diagnosis ${ }^{23}$ and the subsequent risk of progression. ${ }^{24-27}$

At present there is lack of consensus on the 24-h IOP characteristics of NTG patients. ${ }^{28-33}$ Some investigators report that peak IOP in NTG occurs at nighttime. ${ }^{31,33}$ Others, however, disagree suggesting that most NTG patients exhibit their peak 24 -h IOP at daytime. ${ }^{30,34}$ Besides differences in study design and populations, a further reason for such discrepancies in the literature may stem from the fact that systemic medications (prescribed for cardiovascular conditions) can meaningfully influence circadian IOP and OPP rhythm. ${ }^{35}$ Importantly, to date most evidence pertaining to the circadian IOP and OPP characteristics of NTG patients is limited to Asian cohorts. The current study was therefore set out to determine the 24-h IOP and OPP characteristics of newly diagnosed, previously untreated Caucasian NTG patients who were not using systemic vasoactive medications. We also wished to identify any relationship between these characteristics and VF loss parameters at diagnosis.

\section{Materials and methods}

\section{Patients}

This cross-sectional, observational study adhered to the tenets of the Declaration of Helsinki. The participants gave informed consent after the nature and purpose of the trial were fully explained.

The study recruited consecutive, newly diagnosed, previously untreated NTG patients aged $>40$ years who were referred to the Centre for the Study of Glaucoma of the Ophthalmology Department, University of Brescia, Brescia, Italy. The diagnosis of NTG was confirmed by a glaucoma expert after a comprehensive examination that involved a structured ocular and systemic history taking and evaluation of Snellen visual acuity, slit lamp examination, Goldmann applanation tonometry (GAT), gonioscopy, dilated fundoscopy, corneal pachymetry and reliable VF testing (Humphrey 24-2, Humphrey Field
Analyzer (HFA), Humphrey Instruments, San Leandro, CA, USA). Sitting GAT readings had to be $<22 \mathrm{mmHg}$ in two independent measurements $\sim 1 \mathrm{~h}$ apart during office hours in both eyes. To be considered consistent with the diagnosis of glaucoma, VFs had to meet at least two of the following criteria: (1) a cluster of at least three non-edge points with a probability $<5 \%$ on a pattern deviation map including at least one point with a probability $<1 \%$, or a cluster of two non-edge points with a probability $<1 \%$, (2) pattern standard deviation (PSD) outside 95\% of normal limits, and 3) glaucoma hemifield test (GHT) outside normal limits. We included only NTG patients with reliable VFs (defined as VFs with false-positive responses fewer than $15 \%$ and a clear blind spot seen in the printout).

Exclusion criteria for ocular conditions were: history or signs of ocular inflammation, previous intraocular surgery, severe dry eye, corneal conditions, or other anatomical abnormalities preventing reliable tonometry, and the use of any topical medication except artificial tears. Exclusion criteria for systemic conditions were: diseases that could affect the optic nerve such as intracranial neoplasm, multiple sclerosis, diabetes mellitus, or the use of any systemic vasoactive medication within a period of 2 months before evaluation.

\section{Procedures}

Study subjects were admitted for an inpatient 24-h habitual IOP curve in the afternoon of day 1 . The same calibrated Goldmann tonometer (Haag-Streit, Bern, Switzerland) was employed to measure IOP every $2 \mathrm{~h}$ starting at $8 \mathrm{AM}( \pm 30 \mathrm{~min})$ in Day 2. During the night, a calibrated TonoPen tonometer (TonoPen XL; Bio-Rad, Glendale, CA, USA) was used for the 0000, 0200, 0400, and 0600 hours measurements, which were carried out in the supine position before the patient was taken to a nearby examination room for a subsequent Goldmann tonometer measurement. The same well-trained investigator performed all IOP measurements in each patient using the same calibrated Goldmann and TonoPen tonometers. The mean of three consecutive readings was used for analysis. To ensure that the 24-h systolic and diastolic blood pressures (SBP, DBP) measurements would not be unduly influenced by the circadian IOP measurements during hospitalization, automated dynamic BP evaluation was performed after the IOP measurements were completed. Thus, in the morning of Day 3, patients were discharged from the hospital wearing an ambulatory BP monitoring device (TM-2430, A\&D Co., Saitama, Japan) on their nondominant arm programmed to measure 24-h BP. This device relies on the same principle as a conventional mercury sphygmomanometer and uses an appropriately 
sized cuff and a microphone to determine BP automatically. Measurements were taken every $15 \mathrm{~min}$ from 0800 to 2200 hours, and every $30 \mathrm{~min}$ from 2200 to 0800 hours. The device was programmed to repeat BP measurements if they were not accurately recorded. All data were later recovered from the recording chip and were stored on a personal computer. The investigator who performed the IOP measurements and collected the BP data was masked to the patients' glaucoma severity and VF results.

\section{Data assessment}

To calculate 24-h, diurnal and nocturnal IOP and BP parameters, data were averaged over the 24 -hour period, the 0800-2200 hours period and the 1200-0600 hours period, respectively. Habitual position parameters were estimated from pooled measurements in the sitting position from 0800-2200 hours and the supine position from 0000-0600 hours. Habitual IOP was measured with Goldmann tonometer in the diurnal period and with TonoPen in the nocturnal period. Mean arterial pressure (MAP) was calculated as $\mathrm{MAP}=\mathrm{DBP}$ $+1 / 3 \times(\mathrm{SBP}-\mathrm{DBP}) .{ }^{3,36}$ Mean ocular perfusion pressure (MOPP) for the sitting and the supine positions respectively was calculated as $\mathrm{MOPP}_{\text {sitting }}=95 / 140 \times(\mathrm{MAP}-\mathrm{IOP})$ and $\mathrm{MOPP}_{\text {supine }}=115 / 130 \times(\mathrm{MAP}-\mathrm{IOP}) .3,36$ With regard to the evaluation of the nocturnal $\mathrm{BP}$ reduction status (dipping), the following categories were predefined: non-dipping, mild dipping (mean SBP reduction $<5 \%$ with respect to diurnal mean value), physiological dipping (SBP reduction of 5-10\%), and extreme dipping (SBP reduction $>10 \%) .{ }^{37}$

\section{Statistical methods}

Data are presented as mean (SD) for continuous variables, and absolute and relative frequencies for categorical variables. The trend over time in sitting and supine IOP and MOPP values at different time points were assessed with an ANOVA model for repeated measures. The influence of mean deviation (MD) and PSD on 24-h IOP and 24-h MOPP was evaluated with a generalized linear model for repeated measures including both eye measurements. Bonferroni correction was performed for a bilateral test to make allowance for multiple comparisons. Analyses were carried out using SAS statistical software, version 9.2 (SAS Institute Inc., SAS Campus Drive, Cary, NC, USA).

\section{Results}

Sixty-two Caucasian NTG patients (24 men and 38 women) successfully completed the circadian IOP and
BP assessment. Patient demographics and ocular characteristics are presented in Table 1. Mean 24-h SBP, $\mathrm{DBP}$, and MAP are shown in Figure 1. With regard to nocturnal SBP reduction (dipper status), 12 NTG patients (19.35\%) were classified as 'non-dippers', 8 (12.9\%) exhibited mild dipping, 12 (19.35\%) exhibited a physiological dipping, and $30(48.4 \%)$ showed a marked SBP reduction.

Since the percentage of NTG patients with absolute IOP difference between right and left eye above $2 \mathrm{mmHg}$ was only $4.1 \%$ (41 out of 992 measurements) we decided to use mean values of both eyes at each time-point. Sitting and supine IOP measurements over time are presented in Figure 2. Supine IOP was always statistically higher than sitting IOP at each time-point $(P<0.0001)$. Distinct patterns of time-dependent IOP peaks (ie, acrophases) were identified in our cohort. In the seated position, 38 NTG cases (61.3\%) showed a diurnal acrophase, 8 cases (12.9\%) exhibited a nocturnal acrophase, 4 cases $(6.4 \%)$ had a flat rhythm (ie, a minimal difference between peak and trough IOP of less than $2 \mathrm{mmHg}$ ), and in 12 cases $(19.3 \%)$ a biphasic, or polyphasic rhythm was observed

Table 1 Demographic and ocular characteristics of the sample

\begin{tabular}{|c|c|}
\hline Number of patients & 62 \\
\hline \multicolumn{2}{|l|}{ Age in years } \\
\hline Mean (SD) & $59.9(5.5)$ \\
\hline Min/Max & $45 / 70$ \\
\hline \multicolumn{2}{|l|}{ Sex, N (\%) } \\
\hline Female & $38(38.7)$ \\
\hline Male & $24(61.3)$ \\
\hline \multicolumn{2}{|l|}{ CCT RE in $\mu m$} \\
\hline Mean (SD) & $524.2(17.7)$ \\
\hline $\operatorname{Min} / \operatorname{Max}$ & $490 / 565$ \\
\hline \multicolumn{2}{|l|}{ CCT LE in $\mu m$} \\
\hline Mean (SD) & $524.9(17.6)$ \\
\hline $\operatorname{Min} / \operatorname{Max}$ & $490 / 565$ \\
\hline \multicolumn{2}{|l|}{$M D R E$ in $d B$} \\
\hline Mean (SD) & $-5.52(4.74)$ \\
\hline $\operatorname{Min} / \operatorname{Max}$ & $-19.30 /-2.11$ \\
\hline \multicolumn{2}{|l|}{$M D L E$ in $d B$} \\
\hline Mean (SD) & $-5.32(5.71)$ \\
\hline $\operatorname{Min} / \operatorname{Max}$ & $-22.72 /-1.52$ \\
\hline \multicolumn{2}{|l|}{$P S D R E$ in $d B$} \\
\hline Mean (SD) & $3.57(2.52)$ \\
\hline Min/Max & $0.8 / 10.28$ \\
\hline \multicolumn{2}{|l|}{$P S D L E$ in $d B$} \\
\hline Mean (SD) & $3.28(2.62)$ \\
\hline $\operatorname{Min} / \operatorname{Max}$ & $0.93 / 12.4$ \\
\hline
\end{tabular}

Abbreviations: CCT, central corneal thickness; LE, left eye; MD, Humphrey mean deviation; Min-max, minimum-maximum values; PSD, pattern standard deviation; RE, right eye. 


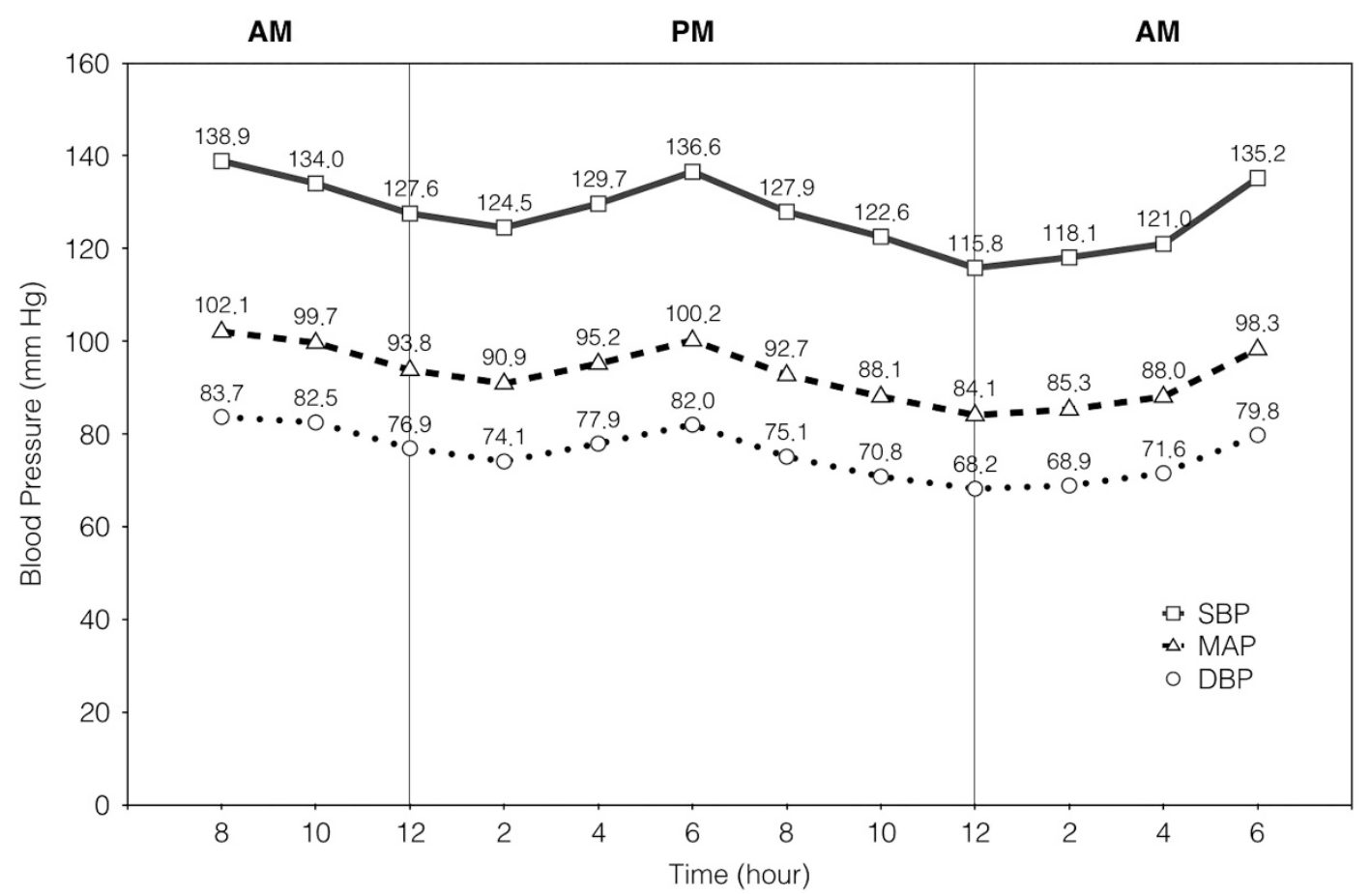

\begin{tabular}{|c|c|c|c|c|c|c|c|c|c|c|c|c|}
\hline & 8AM & $10 A M$ & 12AM & 2PM & 4PM & $6 \mathrm{PM}$ & 8PM & $10 \mathrm{PM}$ & 12PM & $2 A M$ & 4AM & 6AM \\
\hline $\begin{array}{l}\text { Systolic Blood } \\
\text { Pressure (SD) }\end{array}$ & $\begin{array}{l}138.9 \\
(13.1)\end{array}$ & $\begin{array}{l}134.0 \\
(14.8)\end{array}$ & $\begin{array}{l}127.6 \\
(16.9)\end{array}$ & $\begin{array}{l}124.5 \\
(17.2)\end{array}$ & $\begin{array}{l}129.7 \\
(13.9)\end{array}$ & $\begin{array}{l}136.6 \\
(13.6)\end{array}$ & $\begin{array}{l}127.9 \\
(14.7)\end{array}$ & $\begin{array}{l}122.6 \\
(18.0)\end{array}$ & $\begin{array}{l}115.8 \\
(16.5)\end{array}$ & $\begin{array}{l}118.1 \\
(16.3)\end{array}$ & $\begin{array}{l}121.0 \\
(17.2)\end{array}$ & $\begin{array}{l}135.2 \\
(17.5)\end{array}$ \\
\hline $\begin{array}{l}\text { Mean Arterial } \\
\text { Pressure (SD) }\end{array}$ & $\begin{array}{l}102.1 \\
(11.9)\end{array}$ & $\begin{array}{c}99.7 \\
(12.7)\end{array}$ & $\begin{array}{c}93.8 \\
(13.7)\end{array}$ & $\begin{array}{c}90.9 \\
(13.1)\end{array}$ & $\begin{array}{c}95.2 \\
(10.5)\end{array}$ & $\begin{array}{l}100.2 \\
(10.8)\end{array}$ & $\begin{array}{c}92.7 \\
(11.8)\end{array}$ & $\begin{array}{c}88.1 \\
(12.4)\end{array}$ & $\begin{array}{c}84.1 \\
(11.4)\end{array}$ & $\begin{array}{c}85.3 \\
(11.4)\end{array}$ & $\begin{array}{c}88.0 \\
(12.0)\end{array}$ & $\begin{array}{c}98.3 \\
(13.3)\end{array}$ \\
\hline $\begin{array}{l}\text { Diastolic Blood } \\
\text { Pressure (SD) }\end{array}$ & $\begin{array}{c}83.7 \\
(12.2)\end{array}$ & $\begin{array}{c}82.5 \\
(13.2)\end{array}$ & $\begin{array}{c}76.9 \\
(13.2)\end{array}$ & $\begin{array}{c}74.1 \\
(12.5)\end{array}$ & $\begin{array}{c}77.9 \\
(10.6)\end{array}$ & $\begin{array}{c}82.0 \\
(10.8)\end{array}$ & $\begin{array}{c}75.1 \\
(11.6)\end{array}$ & $\begin{array}{c}70.8 \\
(11.3)\end{array}$ & $\begin{array}{c}68.2 \\
(10.0)\end{array}$ & $\begin{array}{c}68.9 \\
(10.1)\end{array}$ & $\begin{array}{c}71.6 \\
(10.5)\end{array}$ & $\begin{array}{c}79.8 \\
(12.5)\end{array}$ \\
\hline
\end{tabular}

Figure 1 Mean values of systolic (SBP) and diastolic blood pressure (DBP) and mean arterial pressure (MAP) over $24 \mathrm{~h}$.

(ie, with differences of peaks $\leq 1 \mathrm{mmHg}$ ). The distribution of IOP peaks in our NTG patients significantly changed when habitual 24-h readings were considered.

Significantly fewer cases $(8,12.9 \%)$ exhibited a diurnal acrophase, whereas 42 cases $(67.7 \%)$ demonstrated a nocturnal acrophase, 1 case $(1.6 \%)$ showed flat rhythm and 11 cases (17.7\%) had biphasic/polyphasic rhythm.

In this NTG cohort, nighttime MOPP values (supine position) were significantly higher than diurnal values (sitting position, $P<0.001$ ). Detailed MOPP results are presented in Figure 3. It is worth noting that in our NTG group there was no statistical association between glaucomatous damage as indicated by VF parameters MD and PSD and either mean habitual 24-h IOP $(P=0.20$ and $P=0.12$ for MD and PSD, respectively) or habitual 24-h MOPP ( $P=0.96$ and 0.29 , for MD and PSD, respectively). Further, no correlation could be established between 24-h habitual IOP or MOPP fluctuation (determined as the SD of readings) and VF MD $(P=0.45$ and $P=0.22$ for 24-h habitual IOP and MOPP, respectively) or $\operatorname{PSD}(P=0.80$ and $P=0.75$ for 24 -h habitual IOP and MOPP, respectively). Similarly, no significant correlation was detected between peak 24-h habitual IOP or MOPP and VF MD $(P=0.26$ and $P=0.88$ for peak 24-h habitual IOP and MOPP, respectively) or PSD $(P=0.31$ and $P=0.18$ for peak 24 -h habitual IOP and MOPP, respectively). Finally, no correlation was detected between trough 24-h habitual IOP or MOPP and MD $(P=0.18$ and $P=0.58$ for trough 24 -h habitual IOP and MOPP, respectively) or PSD $(P=0.49$ and $P=0.85$ for trough 24-h habitual IOP and MOPP, respectively).

\section{Discussion}

Our study describes the 24-h IOP and MOPP characteristics of a large, newly diagnosed, treatmentnaive cohort of Caucasian NTG patients. Previously, several investigators had investigated these parameters in Asian NTG patients ${ }^{29,33}$ or in smaller group of Caucasian patients. ${ }^{34}$ What is novel in this study is that we describe, for the first time, the circadian IOP and MOPP in a meaningful sample of Caucasian NTG patients who were not using vasoactive systemic medications. This may be relevant because previous evidence has demonstrated 


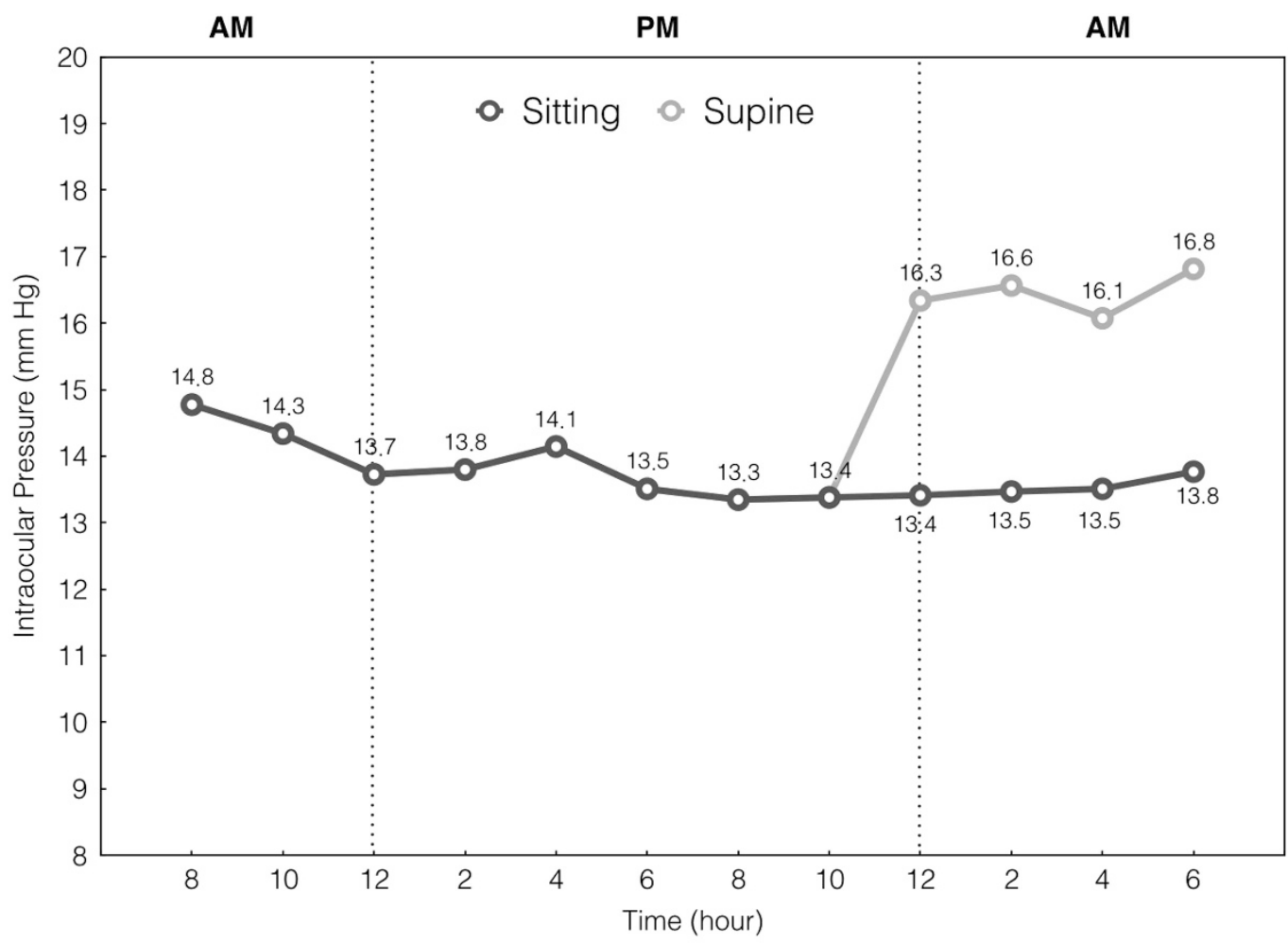

\begin{tabular}{|c|c|c|c|c|c|c|c|c|c|c|c|c|}
\hline & 8AM & 10AM & 12AM & 2PM & 4PM & $6 \mathrm{PM}$ & 8PM & $10 \mathrm{PM}$ & $12 \mathrm{PM}$ & 2AM & 4AM & GAM \\
\hline Sitting IOP (SD) & $\begin{array}{l}14.8 \\
(3.0)\end{array}$ & $\begin{array}{l}14.3 \\
(2.9)\end{array}$ & $\begin{array}{l}13.7 \\
(2.9)\end{array}$ & $\begin{array}{l}13.8 \\
(3.0)\end{array}$ & $\begin{array}{r}14.1 \\
(2.9)\end{array}$ & $\begin{array}{l}13.5 \\
(2.8)\end{array}$ & $\begin{array}{l}13.3 \\
(2.7)\end{array}$ & $\begin{array}{l}13.4 \\
(2.6)\end{array}$ & $\begin{array}{l}13.4 \\
(2.9)\end{array}$ & $\begin{array}{l}13.5 \\
(2.9)\end{array}$ & $\begin{array}{l}13.5 \\
(2.8)\end{array}$ & $\begin{array}{l}13.8 \\
(3.0)\end{array}$ \\
\hline Supine IOP (SD) & & & & & & & & & $\begin{array}{l}16.3 \\
(2.9)\end{array}$ & $\begin{array}{l}16.6 \\
(2.9)\end{array}$ & $\begin{array}{l}16.1 \\
(3.3)\end{array}$ & $\begin{array}{l}16.8 \\
(3.2)\end{array}$ \\
\hline
\end{tabular}

Figure 2 Intraocular pressure (IOP) readings in sitting and supine position during 24-h assessment.

that systemic vasoactive medications influence IOP. ${ }^{35}$ Importantly, medication-induced alterations in systemic BP can adversely influence MOPP. Several studies have linked such hemodynamic alterations to the development and subsequent progression of glaucoma. ${ }^{15-22,24,25}$

In our NTG cohort, IOP readings at night were higher in the supine than the sitting position. Elevated supine IOP can be attributed to the effect of increased episcleral pressure in the supine position. ${ }^{38}$ Interestingly, this is in contrast to the findings of our previous study ${ }^{39}$ with untreated POAG and OHT subjects. Nevertheless, it is important to note that the IOP differences observed between supine and sitting IOP were smaller than those reported by some previous investigators. ${ }^{33,34,38}$ It is also important to highlight that although mean habitual 24-h IOP is higher at night in our NTG patients, four distinct patterns of IOP rhythm were observed: $13 \%$ of our NTG patients had a diurnal acrophase, $68 \%$ had a nocturnal acrophase, $2 \%$ had a flat rhythm and 17\% had a biphasic/ polyphasic rhythm.
Our findings in Caucasian NTG patients are quite similar with those reported in Asian NTG patients by Lee et al. ${ }^{33}$ These authors conducted an in-hospital 24-h study with Korean newly diagnosed, untreated NTG patients and observed that the percentages of patients with a diurnal, nocturnal, or no apparent acrophase in the habitual position were 16,51 and $33 \%$, respectively. ${ }^{33}$ These figures are similar to ours in the habitual position $(13,68,19 \%$, for diurnal, nocturnal and no particular rhythm, respectively). In contrast, in the first study with untreated Caucasian NTG patients performed in a sleep laboratory, Renard et $a l^{34}$ observed that the proportion of their patients with habitual diurnal and nocturnal acrophases was 54.5 and $36.4 \%$, respectively. ${ }^{34}$ However, it should be emphasized that differences in methodology, patient selection and varied definitions of 'nocturnal' and 'diurnal' periods make comparisons between available 24-h studies somewhat difficult.

The present study did not identify a significant relationship between the severity of VF damage at diagnosis and 24-h IOP parameters in this group of NTG 


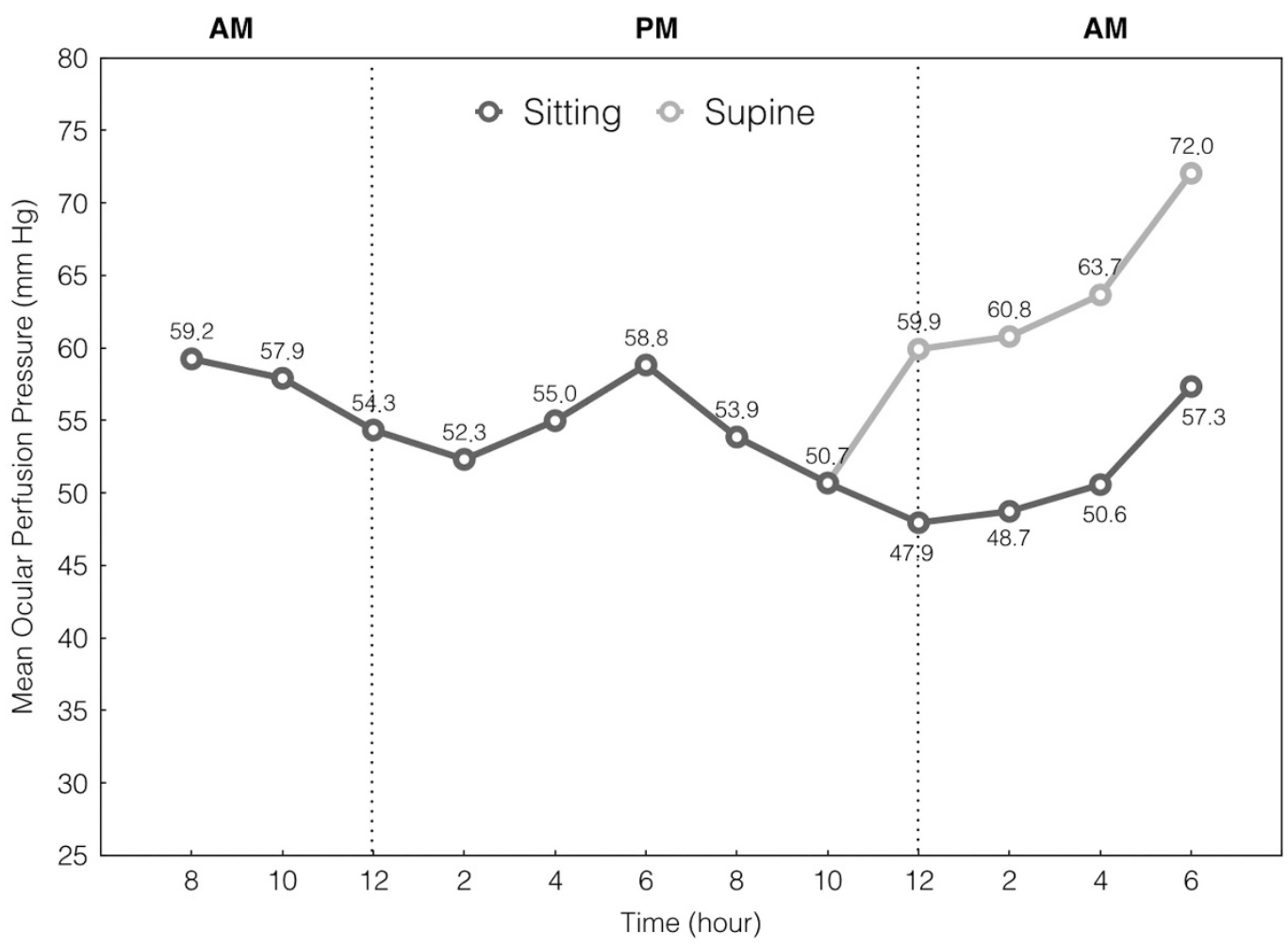

\begin{tabular}{|c|c|c|c|c|c|c|c|c|c|c|c|c|}
\hline & 8AM & 10AM & 12AM & 2PM & 4PM & 6PM & 8PM & $10 \mathrm{PM}$ & 12PM & $2 A M$ & $4 A M$ & 6AM \\
\hline Sitting MOPP (SD) & $\begin{array}{l}59.2 \\
(8.5)\end{array}$ & $\begin{array}{l}57.9 \\
(9.0)\end{array}$ & $\begin{array}{l}54.3 \\
(9.4)\end{array}$ & $\begin{array}{l}52.3 \\
(8.8)\end{array}$ & $\begin{array}{l}55.0 \\
(7.2)\end{array}$ & $\begin{array}{l}58.8 \\
(7.3)\end{array}$ & $\begin{array}{l}53.9 \\
(7.9)\end{array}$ & $\begin{array}{l}50.7 \\
(8.5)\end{array}$ & $\begin{array}{l}47.9 \\
(7.6)\end{array}$ & $\begin{array}{l}48.7 \\
(7.9)\end{array}$ & $\begin{array}{l}50.6 \\
(8.0)\end{array}$ & $\begin{array}{l}57.3 \\
(9.0)\end{array}$ \\
\hline Supine MOPP (SD) & & & & & & & & & $\begin{array}{l}59.9 \\
(9.9)\end{array}$ & $\begin{array}{c}60.8 \\
(10.1)\end{array}$ & $\begin{array}{c}63.7 \\
(10.3)\end{array}$ & $\begin{array}{r}72.0 \\
(11.9)\end{array}$ \\
\hline
\end{tabular}

Figure 3 Mean ocular perfusion pressure (MOPP) in sitting and supine position during 24-h assessment.

patients. To date there has been limited published correlation between the severity of VF damage and 24-h IOP parameters in NTG patients. The investigators of the Low-Pressure Glaucoma Treatment Study could not detect a relationship between any Goldmann-determined diurnal IOP characteristic and VF MD, or corrected PSD at baseline in their NTG patients. ${ }^{40}$ Similarly, no relationship between 24-h IOP parameters and VF indices was found in a large series of Korean NTG patients. ${ }^{33}$ One possible explanation for the lack of such an association is that 24-h IOP characteristics are not related to glaucoma damage in NTG and thus the VF damage is pressure independent. Another potential explanation is that the magnitude of 24-h IOP characteristics (mean, peak, trough and fluctuation) in our NTG patients is relatively small, and therefore it may be harder to detect any effect, if such a relationship does exists. Besides, it should be stressed that important factors unrelated to the glaucoma process itself, such as socioeconomic status or health care access, might be critical determinants of glaucoma damage at presentation. To assess the impact of baseline
IOP and OPP characteristics in our cohort, a longitudinal study would be needed.

The mean 24-h SBP and DBP of our NTG group were 127.7 and $75.9 \mathrm{mmHg}$, respectively. Our BP data concur with those reported in a NTG cohort of 132 Korean patients. ${ }^{23}$ Furthermore, the 24-h MAP documented in our cohort $(93.2 \mathrm{mmHg})$ is fairly similar to the 24-h MAP $\left(94.7 \mathrm{mmHg}\right.$ ) reported by Renard et $a^{34}$ in another group of Caucasian NTG patients.

There is on-going discussion on the precise role and impact of nocturnal systolic BP reduction ('dipping') in glaucoma and especially NTG patients. ${ }^{41}$ Approximately two-thirds of the normal population are believed to exhibit a physiological nocturnal BP reduction, ${ }^{42}$ conceivably elicited by a nocturnal reduction in sympathetic activity. Non-physiological dippers (ie, nondippers and over-dippers) may be at increased risk for cardiovascular morbidity. ${ }^{37,43}$ Previous research suggests that NTG patients may exhibit exaggerated nocturnal BP decreases. ${ }^{44}$ Furthermore, a greater reduction in nocturnal diastolic BP has been linked to glaucoma progression. ${ }^{45,46}$ Recently, Charlson et $a l^{47}$ in a prospective longitudinal 
study of treated NTG patients estimated that the total time in which nocturnal MAP was $10 \mathrm{mmHg}$ below daytime MAP was a reliable predictor of VF deterioration. In the present study, $\sim 20 \%$ of our NTG patients exhibited a normal nocturnal SBP reduction (5-10\%), while $48 \%$ showed a marked SBP reduction $(>10 \%)$. These results are in agreement with those reported by Choi et $a l^{23}$ in Korean NTG patients. In this study, non-dippers (defined as patients with nighttime SBP reduction $<5 \%$ ) and reverse dippers (showing a nighttime elevation of SBP) were collectively classified as non-physiological dippers and constituted $31 \%$ of the NTG cohort under investigation. ${ }^{23}$ Equally in our NTG group, the cumulative percentage of mild dippers and non-dippers was $32 \%$. As different cutoffs have been used by some investigators ${ }^{27,34}$ for the classification of dipping status in NTG, comparisons across studies should be drawn with caution. Besides IOP, it is widely agreed that MOPP is implicated in glaucoma development and progression. ${ }^{3,48}$ A significant body of literature has linked low ocular perfusion pressure to the incidence, ${ }^{16}$ prevalence, ${ }^{17-22}$ and progression of open-angle glaucoma. ${ }^{15}$ For example, the population-based Egna-Neumarkt study found an increased risk of glaucomatous damage for Caucasian POAG (but not NTG) patients with DOPP lower than 70 mmHg. ${ }^{19}$ Had we employed the same formula as Bonomi et $a l^{19}$ (DOPP = DBP - IOP) in our cohort with untreated NTG patients, the mean habitual 24-h DOPP would have been $61.2 \mathrm{mmHg}$ and the nocturnal DOPP $55.7 \mathrm{mmHg}$.

Previous research has suggested that large perfusion pressure fluctuation in NTG patients is associated with disease severity at diagnosis. ${ }^{23}$ In their retrospective chart review, Choi et $a^{23}$ observed that large MOPP

fluctuations were significantly associated with a number of functional (eg, VF MD, PSD, and AGIS score) and structural parameters (polarimetric indices) of glaucomatous damage. ${ }^{23}$ In our investigation, however, there was no direct link between perfusion pressure fluctuation and VF damage parameters. Several reasons may account for this inconsistency. In contrast to that study, our trial excluded patients on antihypertensive, or other vasoactive medications. In addition, differences in ethnicity, sample size, formulae selection, and study design may have a role. On the other hand, our findings are in agreement with those obtained in a Caucasian cohort by Renard et al ${ }^{34}$ who did not observe an association between ocular perfusion pressure and the severity of NTG.

The present investigation has certain limitations. As all participants were Caucasian, the results may not apply to other ethnic NTG populations. As by design enrolled subjects were treatment-naive and were not on systemic vasoactive medication, this cohort may significantly differ from the typical NTG patient encountered in clinical practice. Third, in common with all similar studies, the calculation of MOPP is based on a theoretical formula that may not necessarily describe true ocular perfusion levels at the level of the eye. Therefore, these calculated parameters represent a surrogate of true ocular perfusion pressure. Finally, our investigation did not have a control group. Thus, it is not fully clear to which extent our observations represent NTG-specific characteristics.

In conclusion, our study evaluated the 24-h IOP and MOPP characteristics of a large cohort of treatment-naive, Caucasian NTG patients. Most patients in this cohort exhibited a nocturnal IOP acrophase when their ocular pressure was evaluated in the habitual position. This trial could not establish a link between circadian IOP, or 24-h MOPP characteristics and VF damage at diagnosis. Further research is needed to elucidate how diurnal or 24-h IOP and OPP parameters can be incorporated in current clinical decision-making algorithms.

\section{Summary}

\section{What was known before}

- Previously, several investigators had investigated these parameters in Asian NTG patients or in smaller group of Caucasian patients.

\section{What this study adds}

- What is novel in this study is that we describe, for the first time, the circadian IOP and MOPP in a meaningful sample of Caucasian NTG patients who were not using vasoactive systemic medications.

\section{Conflict of interest}

The authors declare no conflict of interest.

\section{Acknowledgements}

The contribution of the Fondazione Bietti in this paper was supported by Ministry of Health and Fondazione Roma.

\section{References}

1 European Glaucoma Society. Terminology and Guidelines for Glaucoma, 4th ed. PubliComm: Savona, Italy, 2014.

2 Seong GJ, Rho SH, Kim CS, Moon JI, Kook MS, Kim YY et al. Potential benefit of intraocular pressure reduction in normaltension glaucoma in South Korea. J Ocul Pharmacol Ther 2009; 25(1): 91-96.

3 Quaranta L, Katsanos A, Russo A, Riva I. 24-hour intraocular pressure and ocular perfusion pressure in glaucoma. Surv Ophthalmol 2013; 58(1): 26-41.

4 Konstas AG, Quaranta L, Mikropoulos DG, Nasr MB, Russo A, Jaffee HA et al. Peak intraocular pressure and glaucomatous progression in primary open-angle glaucoma. J Ocul Pharmacol Ther 2012; 28(1): 26-32. 
5 Hollo G, Quaranta L, Cvenkel B, Astakhov YS, Teus MA, Kothy $\mathrm{P}$ et al. Risk factors associated with progression in exfoliative glaucoma patients. Ophthalmic Res 2012; 47(4): 208-213.

6 Stewart WC, Day DG, Jenkins JN, Passmore CL, Stewart JA. Mean intraocular pressure and progression based on corneal thickness in primary open-angle glaucoma. J Ocul Pharmacol Ther 2006; 22(1): 26-33.

7 Heijl A, Leske MC, Bengtsson B, Hyman L, Bengtsson B, Hussein $\mathrm{M}$ et al. Reduction of intraocular pressure and glaucoma progression: results from the Early Manifest Glaucoma Trial. Arch Ophthalmol 2002; 120(10): 1268-1279.

8 Dielemans I, Vingerling JR, Wolfs RC, Hofman A, Grobbee $\mathrm{DE}$, de Jong PT. The prevalence of primary open-angle glaucoma in a population-based study in The Netherlands. The Rotterdam Study. Ophthalmology 1994; 101(11): 1851-1855.

9 Zeiter JH, Shin DH, Juzych MS, Jarvi TS, Spoor TC, Zwas F. Visual field defects in patients with normal-tension glaucoma and patients with high-tension glaucoma. Am J Ophthalmol 1992; 114(6): 758-763.

10 Araie M, Yamagami J, Suziki Y. Visual field defects in normal-tension and high-tension glaucoma. Ophthalmology 1993; 100(12): 1808-1814.

11 Collaborative Normal-Tension Glaucoma Study Group. Comparison of glaucomatous progression between untreated patients with normal-tension glaucoma and patients with therapeutically reduced intraocular pressures. Am J Ophthalmol 1998; 126(4): 487-497.

12 Hafez AS, Bizzarro RL, Lesk MR. Evaluation of optic nerve head and peripapillary retinal blood flow in glaucoma patients, ocular hypertensives, and normal subjects. Am J Ophthalmol 2003; 136(6): 1022-1031.

13 Findl O, Rainer G, Dallinger S, Dorner G, Polak K, Kiss B et al. Assessment of optic disk blood flow in patients with open-angle glaucoma. Am J Ophthalmol 2000; 130(5): 589-596.

14 Leske MC. Ocular perfusion pressure and glaucoma: clinical trial and epidemiologic findings. Curr Opin Ophthalmol 2009; 20(2): 73-78.

15 Leske MC, Heijl A, Hyman L, Bengtsson B, Dong L, Yang Z et al. Predictors of long-term progression in the early manifest glaucoma trial. Ophthalmology 2007; 114(11): 1965-1972.

16 Leske MC, Wu SY, Hennis A, Honkanen R, Nemesure B, Group BES. Risk factors for incident open-angle glaucoma: the Barbados Eye Studies. Ophthalmology 2008; 115(1): 85-93.

17 Tielsch JM, Katz J, Sommer A, Quigley HA, Javitt JC. Hypertension, perfusion pressure, and primary open-angle glaucoma. A population-based assessment. Arch Ophthalmol 1995; 113(2): 216-221.

18 Leske MC, Connell AM, Wu SY, Hyman LG, Schachat AP. Risk factors for open-angle glaucoma. The Barbados Eye Study. Arch Ophthalmol 1995; 113(7): 918-924.

19 Bonomi L, Marchini G, Marraffa M, Bernardi P, Morbio R, Varotto A. Vascular risk factors for primary open angle glaucoma: the Egna-Neumarkt Study. Ophthalmology 2000; 107(7): 1287-1293.

20 Quigley HA, West SK, Rodriguez J, Munoz B, Klein R, Snyder R. The prevalence of glaucoma in a population-based study of Hispanic subjects: Proyecto VER. Arch Ophthalmol 2001; 119(12): 1819-1826.

21 Zheng Y, Wong TY, Mitchell P, Friedman DS, He M, Aung T. Distribution of ocular perfusion pressure and its relationship with open-angle glaucoma: the singapore malay eye study. Invest Ophthalmol Vis Sci 2010; 51(7): 3399-3404.

22 Hulsman CA, Vingerling JR, Hofman A, Witteman JC, de Jong PT. Blood pressure, arterial stiffness, and open-angle glaucoma: the Rotterdam study. Arch Ophthalmol 2007; 125(6): 805-812.

23 Choi J, Kim KH, Jeong J, Cho HS, Lee CH, Kook MS. Circadian fluctuation of mean ocular perfusion pressure is a consistent risk factor for normal-tension glaucoma. Invest Ophthalmol Vis Sci 2007; 48(1): 104-111.

24 Sung KR, Cho JW, Lee S, Yun SC, Choi J, Na JH et al. Characteristics of visual field progression in medically treated normal-tension glaucoma patients with unstable ocular perfusion pressure. Invest Ophthalmol Vis Sci 2011; 52(2): 737-743.

25 Sung KR, Lee S, Park SB, Choi J, Kim ST, Yun SC et al. Twenty-four hour ocular perfusion pressure fluctuation and risk of normal-tension glaucoma progression. Invest Ophthalmol Vis Sci 2009; 50(11): 5266-5274.

26 Choi J, Lee JR, Lee Y, Lee KS, Na JH, Han S et al. Relationship between 24-hour mean ocular perfusion pressure fluctuation and rate of paracentral visual field progression in normaltension glaucoma. Invest Ophthalmol Vis Sci 2013; 54(9): 6150-6157.

27 Lee J, Choi J, Jeong D, Kim S, Kook MS. Relationship between daytime variability of blood pressure or ocular perfusion pressure and glaucomatous visual field progression. Am J Ophthalmol 2015; 160(3): 522-537 e521.

28 Kitazawa Y, Horie T. Diurnal variation of intraocular pressure in primary open-angle glaucoma. Am J Ophthalmol 1975; 79(4): 557-566.

29 Ido T, Tomita G, Kitazawa Y. Diurnal variation of intraocular pressure of normal-tension glaucoma. Influence of sleep and arousal. Ophthalmology 1991; 98(3): 296-300.

30 Sacca SC, Rolando M, Marletta A, Macri A, Cerqueti P, Ciurlo G. Fluctuations of intraocular pressure during the day in open-angle glaucoma, normal-tension glaucoma and normal subjects. Ophthalmologica 1998; 212(2): 115-119.

31 Hara T, Hara T, Tsuru T. Increase of peak intraocular pressure during sleep in reproduced diurnal changes by posture. Arch Ophthalmol 2006; 124(2): 165-168.

32 Liu JH, Zhang X, Kripke DF, Weinreb RN. Twenty-four-hour intraocular pressure pattern associated with early glaucomatous changes. Invest Ophthalmol Vis Sci 2003; 44(4): 1586-1590.

33 Lee YR, Kook MS, Joe SG, Na JH, Han S, Kim S et al. Circadian (24-hour) pattern of intraocular pressure and visual field damage in eyes with normal-tension glaucoma. Invest Ophthalmol Vis Sci 2012; 53(2): 881-887.

34 Renard E, Palombi K, Gronfier C, Pepin JL, Noel C, Chiquet $\mathrm{C}$ et al. Twenty-four hour (Nyctohemeral) rhythm of intraocular pressure and ocular perfusion pressure in normal-tension glaucoma. Invest Ophthalmol Vis Sci 2010; 51 (2): 882-889.

35 Khawaja AP, Chan MP, Broadway DC, Garway-Heath DF, Luben R, Yip JL et al. Systemic medication and intraocular pressure in a British population: the EPIC-Norfolk Eye Study. Ophthalmology 2014; 121(8): 1501-1507.

36 Bill A. Physiological aspects of the circulation in the optic nerve In: Heilmann K, Richardson KT (eds). Glaucoma: Conceptions of a Disease. Pathogenesis, Diagnosis, Therapy. Georg Thieme Publ: Stuttgart, Germany, 1978 pp 97-104.

37 Verdecchia P, Schillaci G, Guerrieri M, Gatteschi C, Benemio G, Boldrini $\mathrm{F}$ et al. Circadian blood pressure changes and left 
ventricular hypertrophy in essential hypertension. Circulation 1990; 81(2): 528-536.

38 Mosaed S, Liu JH, Weinreb RN. Correlation between office and peak nocturnal intraocular pressures in healthy subjects and glaucoma patients. Am J Ophthalmol 2005; 139(2): 320-324.

39 Quaranta L, Konstas AG, Rossetti L, Garcia-Feijoo J, O'Brien C, Nasr MB et al. Untreated 24-h intraocular pressures measured with Goldmann applanation tonometry vs nighttime supine pressures with Perkins applanation tonometry. Eye 2010; 24(7): 1252-1258.

40 Greenfield DS, Liebmann JM, Ritch R, Krupin T, LowPressure Glaucoma Study G. Visual field and intraocular pressure asymmetry in the low-pressure glaucoma treatment study. Ophthalmology 2007; 114(3): 460-465.

41 Gherghel D, Hosking SL, Orgul S. Autonomic nervous system, circadian rhythms, and primary open-angle glaucoma. Surv Ophthalmol 2004; 49(5): 491-508.

42 Mallion JM, De Gaudemaris R, Siche JP, Maitre A, Pitiot M. Day and night blood pressure values in normotensive and essential hypertensive subjects assessed by twenty-four-hour ambulatory monitoring. J Hypertens Suppl 1990; 8(6): S49-S55.
43 Shimada K, Kawamoto A, Matsubayashi K, Nishinaga M, Kimura S, Ozawa T. Diurnal blood pressure variations and silent cerebrovascular damage in elderly patients with hypertension. J Hypertens 1992; 10(8): 875-878.

44 Meyer JH, Brandi-Dohrn J, Funk J. Twenty four hour blood pressure monitoring in normal tension glaucoma. $\mathrm{Br} J$ Ophthalmol 1996; 80(10): 864-867.

45 Graham SL, Drance SM, Wijsman K, Douglas GR, Mikelberg FS. Ambulatory blood pressure monitoring in glaucoma. The nocturnal dip. Ophthalmology 1995; 102(1): 61-69.

46 Collignon N, Dewe W, Guillaume S, Collignon-Brach J. Ambulatory blood pressure monitoring in glaucoma patients. The nocturnal systolic dip and its relationship with disease progression. Int Ophthalmol 1998; 22(1): 19-25.

47 Charlson ME, de Moraes CG, Link A, Wells MT, Harmon G, Peterson JC et al. Nocturnal systemic hypotension increases the risk of glaucoma progression. Ophthalmology 2014; 121(10): 2004-2012.

48 Costa VP, Harris A, Anderson D, Stodtmeister R, Cremasco F, Kergoat $\mathrm{H}$ et al. Ocular perfusion pressure in glaucoma. Acta Ophthalmol 2014; 92(4): e252-e266. 